\title{
A ESCOLA ÉTNICA NA CIDADE DE SÃO PAULO E OS PRIMEIROS TONS DE UMA IDENTIDADE ITALIANA (1887-

Claudia Panizzolo ${ }^{1}$

\section{RESUMO}

O objetivo deste artigo é compreender a organização das escolas étnicas italianas estabelecidas na cidade de São Paulo como espaços de constituição de uma identidade nacional, uma italianidade. Para a construção do texto procedeu-se à análise documental de fontes, como estatutos, normas e programas para o funcionamento das escolas italianas; documentos do Ministério das Relações Exteriores da Itália; Anuários das escolas italianas no exterior; ordenamentos legais; jornais, livros, dentre outros. Os limites temporais referem-se ao período demarcado, de um lado, pela criação das escolas, e de outro pela produção de documentação normativa. Recorreu-se à categoria etnia como pilar de sustentação da análise empreendida.

Palavras-chave: escolas étnicas, imigrantes italianos, escola elementar, São Paulo.

${ }^{1}$ Universidade Federal de São Paulo (UNIFESP), São Paulo/SP, Brasil. 


\section{LA ESCUELA ÉTNICA EN LA CIUDAD DE SÃO PAULO Y LOS PRIMEIROS TONOS DE UNA IDENTIDAD ITALIANA (1887 - 1912)}

\section{RESUMEN}

El objetivo de este artículo es comprender la organización de las escuelas étnicas italianas establecidas en la ciudad de São Paulo como espacios de constitución de una identidad nacional, una italianidad. Para la construcción del texto se procedió al análisis documental de fuentes, como estatutos, normas y programas para el funcionamiento de las escuelas italianas; documentos del Ministério de las Relaciones Exteriores de Italia; Anuarios de las escuelas italianas en el exterior; ordenamientos legales; periódicos, libros, entre otros. Los límites temporales se refieren al periodo demarcado, de un lado, por la criación de las escuelas, y de otro por la producción de documentación normativa. Se recorre a la categoría etnia como pilar de sustentación del análisis emprendido.

Palavras-clave: escuelas étnicas, imigrantes italianos, escuela elementar, São Paulo.

\section{THE ETHNIC SCHOOL IN THE CITY OF SÃO PAULO AND THE FIRST TONES OF AN ITALIAN IDENTITY (1887-1912)}

\section{ABSTRACT}

The purpose of this article is to understand the organization of Italian ethnic schools established in the city of São Paulo as spaces for the constitution of a national identity, an Italianity. For the construction of the text were used, documentary analysis of sources, such as statutes, norms and programs for the operation of Italian schools; documents of the Ministry of Foreign Affairs of Italy; Yearbooks of Italian schools abroad; legal orders; newspapers, books, among others. The temporal limits refer to the period marked, on the one hand, by the creation of schools, and another by the production of normative documentation. The ethnicity category was used as a pillar of support for the analysis undertaken.

Keywords: ethnic schools, Italian immigrants, elementary school, São Paulo.

\section{L'ÉCOLE ETHNIQUE DE LA VILLE DE SÃO PAULO ET LES PREMIERS TONS D'UNE IDENTITÉ ITALIENNE (1887-1912)}

\section{RÉSUMÉ}

Le but de cet article est de comprendre l'organisation des écoles ethniques italiennes établies dans la ville de São Paulo comme des espaces pour la constitution d'une identité nationale, d'une italianité. Pour la construction du texte ont été utilisés, une analyse documentaire des sources, telles que les statuts, les normes et les programmes pour le fonctionnement des écoles italiennes; documents du Ministère des affaires étrangères de l'Italie; Annuaires des écoles italiennes à l'étranger; ordres juridiques; journaux, livres, entre autres. Les limites temporelles se réfèrent à la période marquée, d'une part, par la création d'écoles, et d'autre part, par la 
production de documentation normative. La catégorie ethnique a été utilisée comme pilier de l'analyse entreprise.

Mots-clés: écoles ethniques, immigrants italiens, école primaire, São Paulo. 


\title{
CONSIDERAÇÕES INICIAIS
}

Em 10 de março de 1884, o moderno navio Nord America estava atracado no porto de Gênova. Com 127 metros de comprimento e 15 de largura e quase 200 tripulantes, era um navio a vapor, equipado e seguro, ao contrário de seus congêneres, que ofereciam precárias condições de segurança e naufragavam no Oceano Atlântico com centenas de emigrantes a bordo. $\mathrm{O}$ destino era Montevidéu no Uruguai. Assim que a ponte foi erguida, as amarras retiradas, a escada suspensa e o apito soado, o cenário era de agitação e tristeza:

\begin{abstract}
Então algumas mulheres desataram a chorar, os jovens que estavam rindo ficaram sérios, e alguns homens barbudos, até então impassíveis, foram vistos passar as mãos nos olhos. Essa agitação tinha um contraste um tanto estranho em relação à calmaria das despedidas dos marinheiros e oficiais a seus amigos e parentes reunidos no cais, como se o navio estivesse partindo para La Spezia [...]. As luzes já brilhavam na cidade. O navio deslizava lentamente em meio à semiescuridão do porto, quase às escondidas, como se tivessem levando embora um carregamento de carne humana roubada. Fui para a proa, onde havia mais pessoas; todas estavam viradas para a terra firme, olhando para o anfiteatro de Gênova, que se iluminava rapidamente. Poucas falavam, e baixinho. Aqui e ali, em meio à escuridão, vi mulheres sentadas com crianças apertadas junto ao peito, com a cabeça abandonada entre as mãos. Perto do castelo da proa uma voz rouca e solitária gritou em tom de sarcasmo: - Viva a Itália! - e levantando os olhos, vi um velho alto que mostrava o punho para a pátria. Quando deixamos o porto já era noite (DE AMICIS, 2017, p. 22-3).
\end{abstract}

Desta forma Edmondo de Amicis (1846-1908) intelectual engajado com o movimento político, militar, social e cultural que reivindicava a unificação da Itália, denominado Risorgimento, autor de obras como L'ídioma gentile e o consagrado Cuore, descreveu a partida dos emigrantes do porto de Gênova, na Itália, no primeiro romance da emigração italiana. Trata-se do livro Sull'Oceano publicado em 1889 e que, em apenas duas semanas alcançou dez edições, o que merece destaque, ao se considerar a restrita disseminação do idioma italiano e os baixos índices de alfabetização entre a população da península, à época. 
Poma (2017, p. 7) destaca que Sull'Oceano desempenha importante papel de denúncia social acerca da "emigração em sua fase mais dura e dramática, a da partida e separação da própria terra para enfrentar um futuro incerto e cheio de incógnitas". A publicação do livro precede a Lei de 31 de janeiro de 1901, $\mathrm{n}^{0} 23$ sobre a imigração e seu Regulamento; a Lei de $1^{\circ}$ de fevereiro de 1901, $\mathrm{n}^{0} 24$ sobre a tutela de remessas e de economias dos emigrantes italianos no exterior e seu Regulamento, dentre outros que buscavam garantir melhores condições higiênicas e sanitárias de viagem e uma maior tutela do emigrante a bordo dos navios ${ }^{2}$, sem deixar no entanto, de assegurar os interesses das companhias de navegação, que alcançaram franco desenvolvimento devido ao fluxo migratório transoceânico a partir dos portos de Gênova, Napoli e Palermo.

Com o escritor, embarcaram 50 passageiros na primeira classe, 20 na segunda e 1600 na terceira, nesta com condições precárias de higiene e segurança, bastante diversas das outras duas classes. A destinação dos passageiros era predominantemente a Argentina, e alguns poucos o Uruguai.

Segundo Marcolini (2017, p. 11) a composição no navio expressa "um microcosmo da nova nação que estava tomando corpo depois da unificação da Itália, em 1861", reproduzindo assim, a estrutura social italiana de fins do século XIX, "a burguesia proprietária na primeira classe, o estrato médio (artesãos, pequenos comerciantes, trabalhadores qualificados) na segunda e o campesinato na terceira" (p. 11). Na bem-humorada descrição de De Amicis uma divergência quanto aos ocupantes da primeira e segunda classe:

Na terceira classe estava o povo, a burguesia na segunda, a aristocracia na primeira; o comandante e os oficiais superiores representavam o Governo; o Comissário, a magistratura; a função da imprensa estava representada prelo registro das reclamações e cumprimentos abertos na sala de jantar; além dos próprios passageiros que, às vezes, sem saber o que fazer para acabar com o tédio fundavam um jornal

\footnotetext{
2 A esse respeito consultar o Bolletino del Ministero degli Affari Esteri, 14 agosto 1901, fascicolo 204; Bolletino della emigrazione, 1902, anno 1.
} 
quotidiano (DE AMICIS, 2017, p.38).

Após a unificação da Itália ocorreu um êxodo de milhares de camponeses, trabalhadores rurais, artesãos, trabalhadores de pouca qualificação e desempregados que emigraram em busca de uma vida melhor. A Itália que De Amicis encontra a bordo do navio Nord America, denominado de Galileo no livro, é predominantemente pobre e analfabeta, composta por "trabalhadores robustos de olhos tristes, velhos maltrapilhos e sujos, mulheres grávidas, moças alegres, rapazolas ligeiramente bêbados, homens grosseiros em mangas de camisa, e crianças e mais crianças...” (DE AMICIS, 2017, p. 20), de maioria do norte da Itália, "e oito em cada dez eram da zona rural” (DE AMICIS, 2017, p. 36). Estes emigrantes se comunicavam em seus próprios dialetos, o que confirmava que, ao menos da perspectiva da unidade de idioma, a Itália ainda não era efetivamente uma nação. Em grande parte, estas pessoas se encontravam desiludidas e desesperançadas com o advento da recém unificação que não lhes assegurou melhores condições de vida e de trabalho. A saudação e o punho descritos anteriormente na citação de De Amicis são expressões, por meio do sarcasmo e do gesto de rancor, de um ressentimento que se fazia presente.

Sull'Oceano, embora não seja o objeto de investigação deste trabalho, é uma importante fonte sobre a experiência emigratória da Península rumo à América. "Fazer a América”, expressão bastante utilizada à época, compreendia como destinos os Estados Unidos que atraíram cerca de 33 milhões, a Argentina 5,4 milhões, o Canadá 4,5 milhões, todos considerados mais atrativos que o Brasil, provavelmente pelas semelhanças climáticas, mas principalmente, pelo fato de que o problema da escravidão já estava há muito solucionado ou sequer existisse. Ainda assim, para cá vieram 3,8 milhões de pessoas. De acordo com Bassanezi et alii (2008) a imigração para o Brasil3 só "foi possível graças à imigração subsidiada articulada pelo governo para atrair imigrantes, que não

\footnotetext{
3 Em 1902, a Itália, por meio do Decreto Prinetti proibiu a emigração subvencionada para o
} Brasil devido ao excessivo endividamento dos emigrantes com os empregadores brasileiros. 
tinham assim que arcar a priori com as despesas de viagem e alojamento inicial.” (p. 14).

Entre fins do século XIX e começo do século XX, São Paulo era uma das maiores cidades de imigração do mundo. Entre 1880 e 1924, entraram no Brasil 3.396.366 imigrantes, dos quais 1.331.158 eram italianos4. De acordo com Hall (2004) dos 4,8 milhões de pessoas que vieram para o Brasil entre 1820 e 1949, mais da metade entrou pelo Estado de São Paulo e foram levadas principalmente para as fazendas de café paulistas5 e para os núcleos de colonização no Sul e Sudeste do país.

Os emigrantes saídos da Península Itálica que adentraram e ocuparam diferentes lugares e espaços em terras paulistas e paulistanas foram muito lentamente se constituindo como italianos. Os que foram trabalhar nas fazendas de café, nas colônias ou que viveram nas áreas urbanas, na capital de São Paulo, no confronto cotidiano com os brasileiros, com os imigrantes de outras nacionalidades, não eram vistos e reconhecidos como campânios, lucanos, calabreses, piemonteses, toscanos, vênetos, etc, mas sim, como italianos. No entanto, segundo Trento (1988, p.161-2) somente a partir do século XX o sentimento de pertencimento ao mesmo país e, de uma identidade comum, se fortalece, em muito favorecido "pela consciência de se saberem estrangeiros e pela uniformidade que era atribuída aos imigrantes pela opinião pública brasileira".

Ainda que entre os imigrantes continuassem a existir vínculos de seus lugares de origem, seus dialetos, costumes, enfim, marcas de suas culturas, em muitos momentos, uniram-se, quer seja pelas dificuldades enfrentadas diuturnamente, quer pela defesa de seus interesses como comerciantes,

\footnotetext{
4 Vários foram os motivos do que ficou conhecido como período da Grande Emigração Italiana ocorrida entre as datas-marco da unificação italiana (1861) e do final da Primeira Guerra Mundial (1918); ganhou contornos nítidos a partir de fins da década de 1870, tornando-se fenômeno de massa entre 1887 e 19024. Trento $(1988,2009)$ e Cenni (2003) apontam a miséria como a causa principal.

5 A respeito do trabalho nas lavouras de café no interior do estado de São Paulo consultar: ALVIM (1986); CENNI (2003); TRENTO (1988).
} 
artesãos, operários, agricultores etc. De acordo com Truzzi (2016, p. 41) "os primeiros tons de uma identidade italiana ainda em formação, impactada inicialmente pelas próprias consequências do fenômeno migratório" constituiuse em um longo e difícil processo, para o qual contribuíram, a imprensa, as associações étnicas e as escolas étnicas.

A imprensa constitui uma das mais distintivas manifestações culturais dos imigrantes italianos e seus descendentes. Merece destaque a presença dos italianos na imprensa periódica publicada em italiano no Brasil, que abrangia um conjunto amplo de tendências ideológicas que além da socialista e da anarquista "incluía liberais, católicos, monarquistas, republicanos e, no período entre as duas guerras, também fascistas e antifascistas" (TRENTO, 2000, p. 106). Até 1940 foram publicados 295 periódicos em italiano de tipos diversos, somente na capital de São Paulo (CENNI, 2003; TRENTO, 2013).

Além da imprensa periódica que procurava "suscitar nos conterrâneos o orgulho de ser italiano, e de ter feito progredir, com sua presença e seu trabalho, a economia e a sociedade brasileiras" (TRENTO, 2016, p. 12), as inúmeras associações étnicas também contribuíram para difundir o sentimento de pertencimento e de identidade italiana.

Luca (1990) e Biondi (2011) apresentam a expressiva presença de Sociedades Italianas de Mútuo Socorro fundadas em São Paulo, capital. Biondi (2011) localiza entre 1878 e 1924 a existência de 44 sociedades mutualistas em São Paulo e nos centros urbanos periféricos de Santo Amaro, São Bernardo e São Caetano, enquanto Luca (1990) informa a existência de 34 SIMS entre 1878 e 1928 cujas sedes eram em São Paulo.

Além da preservação da solidariedade étnica manifestada por meio da troca de experiência entre os sócios, da oportunidade de falar a língua materna, e de serviços de assistência, algumas das SIMS buscavam propiciar instrução aos sócios. Além do ensino de música e de línguas, da promoção de palestras e 
conferências, algumas difundiam a instrução primária ${ }^{6}$.

Nos diferentes bairros habitados por imigrantes, foram criadas escolas com marcas étnicas. Compreendê-las como espaços de constituição da italianidade, por meio e para além da aprendizagem dos saberes elementares do ler, escrever e calcular é o objetivo deste trabalho. O presente texto apresenta resultados ainda preliminares de pesquisa acerca do processo escolar entre imigrantes italianos e descendentes estabelecidos em São Paulo, capital, entre as últimas três décadas do século XIX e as duas primeiras décadas do século XX.

Ao longo do texto procurou-se responder às questões que intrigam e suscitam as investigações sobre esta temática: Quantas e quais eram as escolas italianas na cidade de São Paulo? Havia um programa curricular norteador das práticas escolares? Os conteúdos ensinados atendiam aos ordenamentos legais brasileiros ou italianos? Como as escolas étnicas italianas contribuíram para a constituição de uma identidade étnica italiana, de uma italianidade?

Para a construção do texto procedeu-se à análise documental, especialmente das seguintes fontes: Normas para o funcionamento das escolas italianas no estado de São Paulo; Programa para as escolas elementares italianas do estado de São Paulo; Estatuto da Associação de professores italianos de São Paulo; documentos do Ministério das Relações Exteriores da Itália; Anuários das escolas italianas no exterior; ordenamentos legais; jornais, livros, dentre outros.

Os limites temporais deste texto referem-se ao período demarcado, de um lado, pela chegada expressiva de imigrantes vindos da Península Itálica e criação de escolas étnicas em São Paulo (cidade), e de outro pela produção de documentação normativa e fiscalizadora de tais escolas.

Buscou-se analisar as iniciativas escolares, para assim desvelar as pistas e os sinais do processo escolar étnico, de escolas, portanto, vincadas pela

\footnotetext{
6 Panizzolo $(2017,2016 \mathrm{~b})$ realizou pesquisa sobre a Escola mantida pela Società di Mutuo Soccorso Principe di Napoli, fundada em 1892 no núcleo colonial de São Caetano- SP.
} 
etnicidade. De acordo com Poutignat e Streiff-Fenart (2011) a etnicidade não se refere a um atributo biológico, adquirido desde o nascimento, ao contrário, trata-se de um processo contínuo de construção e reconstrução. Neste sentido, não existem categorias, que definam à priori, o pertencimento de um indivíduo a este ou àquele grupo. Nessa mesma direção apontam Malikoski e Kreutz (2014, p. 73) que “o processo escolar étnico forma-se na interação dialógica que determinado grupo possui de si próprio e na consciência do que é característico de seu processo identitário e cultural”.

A categoria etnia torna-se assim pilar de sustentação da análise empreendida e é tomada de empréstimo de Kreutz (2014, p.36), para quem:

\begin{abstract}
A opção por etnia, como uma categoria de análise em educação, não se opõe às e nem substitui as categorias de classe, de gênero e outras. Ajuda, sim, a ampliar a ótica de análise, com potencialidade para detectar aspectos da trama das ações e das relações humanas a partir de vivências e simbologias. Significa um avanço no esforço metodológico que ajuda a compreender de que forma os processos educacional e escolar têm se desenvolvido em relação à diferenciação cultural.
\end{abstract}

O texto está organizado7 em dois tópicos principais, a saber: as escolas italianas na cidade de São Paulo; a construção da identidade nacional italiana no caráter das crianças e adolescentes e por fim, as considerações finais.

\title{
AS ESCOLAS ITALIANAS NA CIDADE DE SÃO PAULO
}

Em 1889 o Ministério da Relações Exteriores publicou o primeiro número do Anuário das escolas coloniais italianas (1888-1889) ${ }^{8}$. O documento de duzentas e cinco páginas apresenta um breve histórico sobre como o governo

\footnotetext{
7 Os textos em italiano foram por mim traduzidos e os originais inseridos em nota de rodapé. 8 No original Annuario delle scuole colonial per l'anno finanziario e scolastico 1888-89.
} 
tem promovido a difusão da língua e da cultura italiana e a instrução das colônias, a partir de três ações distintas. A primeira, por meio de subsídio ${ }^{9}$ fixo ou extraordinário às escolas italianas no exterior, sejam privadas, de colonos ou de missões religiosas italianas; a segunda por meio de subsídio às instituições não italianas, que, no entanto, ensinam a língua italiana; e por fim, mantendo escolas, que são denominadas governativas, em diversas localidades.

Em seguida o documento apresenta o que denomina escolas coloniais, que muito diferente do que o nome sugere, não estão localizadas nos territórios geopoliticamente dominados pela Itália. Depreende-se que se trata em verdade, de países em que os emigrantes da península estabeleceram colônias imigratórias. Assim por exemplo, há escolas na Argentina, Brasil, Egito, França, Grécia, Inglaterra, Peru, Romênia, Espanha, Estados Unidos, Suíça, Tunísia, Turquia e Uruguai. No caso específico do Brasil é indicada a existência de escolas na província do Rio Grande do Sul.

Dentre as escolas coloniais há as subsidiadas na Argentina, Brasil, Egito, França, Inglaterra, Peru, Estados Unidos, Suiça, Turquia e Uruguai. No Brasil, são indicadas, ainda que sem nomear individualmente, escolas na província do Rio Grande do Sul e escolas sociais no Rio de Janeiro.

As escolas governativas que são as que gozam de apoio direto do governo italiano como o pagamento de salários, envio de pessoal, material escolar etc. foram criadas no Egito, na Grécia, na Tunísia, na Turquia e na então chamada Tripolitania.

Na parte final do Anuário há um apêndice contendo a contabilidade dos custos com as escolas no exterior; a lista dos livros de texto a serem distribuídos; as atribuições dos cônsules e diretores para a administração das escolas italianas no exterior; premiações escolares; quadro dos subsídios atribuídos, e, aviso de concurso para professor no exterior.

\footnotetext{
9 Panizzolo (2018a, 2016a) e Mimesse (2012) realizaram estudos sobre as políticas da Itália para o envio de subsídios para as escolas italianas em São Paulo.
} 
Embora na cidade de São Paulo já funcionasse desde 1887 a escola Sempre Avanti Savoia! e desde 1889 as escolas Italiana e Regina Margherita, conforme lê-se na tabela 1 , nenhuma delas foi computada nos quadros existentes no Anuário de 1888-1889.

Tabela 1- Escolas italianas na cidade de São Paulo

\begin{tabular}{l|l|l|l}
$\begin{array}{l}\text { ANO DE } \\
\text { CRIAÇÃO }\end{array}$ & NOME DA ESCOLA & $\begin{array}{l}\text { ANO DE } \\
\text { CRIAÇÃO }\end{array}$ & NOME DA ESCOLA \\
\hline \multicolumn{1}{c|}{ s d } & Aporti Ferrante & 1898 & Principe di Piemonte \\
\hline 1887 & Sempre Avante, Savoia! & 1900 & Alessandro Manzoni \\
\hline 1889 & Italiana & 1900 & Elena di Montenegro \\
\hline 1889 & Regina Margherita & 1900 & Francesco Fiorentino \\
\hline 1891 & Immacolata & 1901 & Italiana \\
\hline 1891 & Luigi Settembrini & 1901 & Vittorino da Feltre \\
\hline 1891 & Vittorio Emanuele II & 1902 & Italo-Francese \\
\hline 1893 & Cornelia Gracco & 1902 & Santa Lucia \\
\hline 1893 & Dante Alighieri & 1902 & Regina Margherita \\
\hline 1895 & Elena Cairoli & 1903 & Dio e Popolo \\
\hline 1895 & Vittorio Alfieri & 1903 & Regina Margherita \\
\hline 1896 & Roma Intangibile & 1904 & Princ. Mafalda di Savoia \\
\hline 1897 & Italia & 1904 & Regina Elena \\
\hline 1897 & Unione Italiana & 1904 & Stella d'Italia \\
\hline 1898 & Dio e Patria & 1904 & Studio e Lavoro \\
\hline 1898 & Giovanni Bovio & 1905 & Italiana \\
\hline 1898 & Giuseppe Gallian & 1905 & Lodovico Antonio Muratori \\
\hline 1898 & Principe di Piemonte & 1905 & Principe Amedeo \\
\hline 1898 & Umberto I & 1905 & Vittorio Emanuele III \\
\hline 1898 & Vittoria Colonna & & \\
\hline
\end{tabular}

Fonte: Tabela elaborada pela autora com base nos dados reportados no Elenco delle scuole italiane nello stato di S. Paolo,1905; FANFULLA, 1906, p. 801.

No ano de 1898 foi publicada uma matéria intitulada As escolas italianas de São Paulo ${ }^{10}$ no Almanaco del Fanfulla afirmando que as escolas italianas em São Paulo são numerosas, e deixadas quase inteiramente à iniciativa privada. Esta afirmação se confirma na tabela 1, onde se lê que até 1898 já estavam em funcionamento vinte escolas privadas na cidade, número que dobra até 1905.

${ }^{10}$ No original Le scuole italiane di S.Paolo. 
Nos anos subsequentes os proprietários e professores destas escolas, ao que parece, em busca de uma melhor organização para seu funcionamento, e também como mecanismo de proteção e apoio mútuo, se organizaram em torno da Associação dos professores italianos de São Paulo ${ }^{11}$. Em 1901 publicaram o documento Programas das escolas da Associação dos professores italianos de São Paulo ${ }^{12}$ organizado em dois cursos, um denominado inferior com a $1^{\mathrm{a}}, 2^{\mathrm{a}} \mathrm{e}$ $3^{\mathrm{a}}$ classe e um denominado superior, com a $4^{\mathrm{a}}$ e $5^{\mathrm{a}}$ classe, equivalendo cada classe a um ano escolar.

O Programa é proposto para as cinco classes e apresenta a Língua Italiana ( $1^{\mathrm{a}}, 2^{\mathrm{a}}, 3^{\mathrm{a}}, 4^{\mathrm{a}}, 5^{\mathrm{a}}$ classes); Aritmética $\left(1^{\mathrm{a}}, 2^{\mathrm{a}}, 3^{\mathrm{a}}, 4^{\mathrm{a}}, 5^{\mathrm{a}}\right.$ classes); Caligrafia ( $1^{\mathrm{a}}, 2^{\mathrm{a}}, 3^{\mathrm{a}}, 4^{\mathrm{a}}, 5^{\mathrm{a}}$ classes); Noções variadas $\left(1^{\mathrm{a}}, 2^{\mathrm{a}}, 3^{\mathrm{a}}, 4^{\mathrm{a}}, 5^{\mathrm{a}}\right.$ classes $)$; História ( $3^{\mathrm{a}}, 4^{\mathrm{a}}, 5^{\mathrm{a}}$ classes); Geografia ( $3^{\mathrm{a}}, 4^{\mathrm{a}}, 5^{\mathrm{a}}$ classes); Direitos e DeveresBrasil ( $3^{\mathrm{a}}, 4^{\mathrm{a}}, 5^{\mathrm{a}}$ classes); Língua Portuguesa ( $3^{\mathrm{a}}, 4^{\mathrm{a}}, 5^{\mathrm{a}}$ classes); História do Brasil ( $3^{\mathrm{a}}, 4^{\mathrm{a}}, 5^{\mathrm{a}}$ classes); Geografia ( $3^{\mathrm{a}}, 4^{\mathrm{a}}, 5^{\mathrm{a}}$ classes). Havia ainda as matérias de Desenho; Canto, Ginástica, Trabalho Manual, sem, no entanto, programa elencado e indicação da classe a ser ofertada.

Cabia ao ensino da Língua Italiana e ao estudo da História e Geografia aproximar as crianças, nascidas ou não na Itália, daquela que era considerada a pátria, o país a ser amado, lembrado e respeitado, a Itália. Assim, o Programa prevê por exemplo, para o estudo de História, para a $3^{\mathrm{a}}$ classe, o estudo do Risorgimento italiano entre 1848 e 1870; para a $4^{\text {a }}$ classe fatos e homens notáveis da história romana e da história medieval, bem como o estudo sobre italianos célebres da literatura, das artes e das ciências; para a $5^{\mathrm{a}}$ classe o estudo de fatos e homens notáveis da História Moderna, além dos fatos principais do Risorgimento Italiano. Com relação à Geografia, para a $3^{\mathrm{a}}$ e $4^{\mathrm{a}}$ classes a descrição da Itália; para a $5^{\mathrm{a}}$ classe o estudo do Reino da Itália e a emigração italiana para a América.

Em 1902 a Associação publica o Estatuto da Associação dos

\footnotetext{
${ }_{11}^{11}$ No original Associazione fra gl'Insegnanti italiani di S.Paolo.

12 No original Programmi delle scuole dell' Associazione fra gl'Insegnanti italiani di S.Paolo.
} 
professores italianos de São Paulo ${ }^{13}$ (1902, p. 1). Em seu primeiro parágrafo define sua finalidade:

\begin{abstract}
A sociedade se propõe o escopo de irmanar os professores do estado de São Paulo; de difundir a língua e a cultura pátria, constituindo-se em um Comitê da Dante Alighieri de Roma; de dar um endereço mais estável às várias escolas, procurando reagrupar e fundir em um instituto melhor provido de professores, de materiais escolares, de locais, etc.; de recolher doações e ofertas em livros e em dinheiro ao escopo de formar um gabinete de leitura, de organizar conferências, festas escolares, etc. ${ }^{14}$
\end{abstract}

O Estatuto informa ainda que a participação na Associação estava vinculada à anuidade que todos deveriam pagar de seis mil reis, tendo como data limite, o dia 30 de junho de cada ano. A administração da Associação é confiada a uma Comissão denominada de Deputazione Scolastica ${ }^{15}$, composta por quatro membros ${ }^{16}$, sendo ao menos dois professores associados, e tendo por presidente o cônsul geral da Itália. Dentre as competências da Deputazione Scolastica encontram-se destacadas a distribuição de material escolar e a repartição dos subsídios enviados pelo Ministério das Relações Externas. No documento Elenco das escolas italianas pertencentes à Associação dos professores italianos de São Paulo ${ }^{17}$ pode-se ver a significativa adesão das escolas (tabela 2)

13 No original Statuto della Associazione fra gl'Insegnanti italiani di S.Paolo.

14 No original "La Società si propone lo scopo di affratellare gl'insegnanti italiani dello Stato di S.Paolo, di diffondere la língua e la cultura patria, costituendosi in Comitato della Dante Alighieri di Roma, di dare um indirizzo piú stabile alle varie scuole, cercando di raggruparle e fonderle in Istituto meglio provvisti d'Insegnanti, di materiale scolastico, di locali, etc, di raccogliere doni e oferte in libri e in danaro allo scopo di formare un gabinetto di lettura, di organizare conferenza, feste scolastiche, etc. (p.1)"

${ }^{15}$ Será mantido o nome original italiano

${ }^{16}$ Em documento do Ministério das Relações Externas de 21 de abril de 1903 há informação de que a Deputazione Scolastica passou a ser composta ao invés de quatro, por oito membros, sem a exigência de ser professor e nem associado.

17 No original Elenco delle scuole italiane appartenienti alla Associazione fra gl'Insegnanti italiani in S.Paolo divise per Distretti Consolari. 
Tabela 2- Escolas italianas participantes da Associação dos professores italianos.

\begin{tabular}{|c|c|c|c|}
\hline $\begin{array}{l}\text { NOME DA } \\
\text { ESCOLA }\end{array}$ & ENDEREÇO & $\begin{array}{l}\text { NOME DA } \\
\text { ESCOLA }\end{array}$ & ENDEREÇO \\
\hline Americo Vespuccio & Visconde $111 \mathrm{~A}$ & Italiana & S. Paulo \\
\hline Carrara & S. Gaetano 62 & Italiana & Independência \\
\hline Cristoforo Colombo & Xavier Toledo 58 & Italiana & Fortaleza 121 \\
\hline Dante Alighieri & Paraiso & Italiana & Graça 7 \\
\hline Dio e Patria & Ladeira Santa Efigênia & Italiana & Sacramento \\
\hline Gaetani Agnese & Cofae 9A & Italiana & Bom Retiro 50 \\
\hline Giordano Bruno & Carlos Gomes 76 & Italiana & Fortaleza 19 \\
\hline Giovanni Bovio & Gasômetro 120 & Italiana & S. Caetano \\
\hline Giuseppe Garibaldi & Imigrantes & L'educatore Italia & Ipiranga \\
\hline Giuseppe Verdi & Cesario Motta 57 & L'educatore Italia & Monsenhor Andrada 8 \\
\hline Immacolata & A 7 de Abril 20 & Massimo Oreghi & Ladeira do Piques 15B \\
\hline Italiana & Mooca 72 & Patria e Lavoro & Manoel \\
\hline Italiana & Vergueiro 236A & Principe Amedeo & Major Diogo 88 \\
\hline Italiana & Saiao 75 & $\begin{array}{ll}\text { Principi } & \text { di } \\
\text { Carignano } & \end{array}$ & Amaral Gurgel 52 \\
\hline Italiana & Coronel Maria 26 & Regina Elena & Villa Marianna \\
\hline Italiana & S. Francisco 32 & Regina Elena & Gasômetro 1 \\
\hline Italiana & Lapa & Regina Margherita & Italianos \\
\hline Italiana & Gomes Cardim & Regina Margherita & M. Andrade 48 \\
\hline Italiana & Barão de Jundiai & Roma Intangibile & Santo Antonio 119 \\
\hline Italiana & Barra Funda 168 & Silvio Pellico & Santo Antonio 141 \\
\hline Italiana & 21 de Abril $42 \mathrm{~A}$ & Umberto I & Silvia Simosi 9A \\
\hline Italiana & Visconde de Parnaíba 37 & Umberto I & Souza Lima 9A \\
\hline Italiana & S. Antonio 154 & Vittorio Alfieri & Benjamim Oliveira 61 \\
\hline Americo Vespuccio & Visconde $111 \mathrm{~A}$ & & \\
\hline
\end{tabular}

Fonte: Tabela elaborada pela autora com base nos dados reportados em Elenco delle scuole italiane appartenienti alla Associazione fra gli insegnanti italiani in S. Paolo,1903.

A experiência de uma quase autogestão enfrentou percalços e teve vida curta. Em um documento de 1 de março de 1904, o secretário Sebastiano Navasques apresenta um breve quadro da situação ao cônsul italiano em São Paulo, Gherardo Pio di Savoia. Informa que há um descontentamento de parte dos professores e proprietários de escolas, inclusive denúncia de ilegalidade nos procedimentos de aprovação do Estatuto denunciados pelo professor Michele Coralbo, segundo o qual: “...o estatuto não foi discutido, mas imposto pela anterior Deputazione Scolastica de 1902, e de seu Presidente, o R. Consul Geral 
Attilio Monaco"18. Com este cenário o secretário emite seu parecer:

Certo é, que será vantajoso reunir todos os professores sob a autoridade consular, e fazendo desaparecer todas as associações e todas as lutas pessoais; [...] todos possam usufruir os benefícios concedidos do pátrio governo, benefícios que não só se refletem nos mestres, mas nos alunos, nas famílias, em todos os italianos, que com o reflorir das nossas escolas, farão conhecer, ainda que longe da pátria, se recordam dela, e querem que seus filhos aprendam a conhece-la, a amá-la, a respeitá-la. (DISPACCIO, 1904)

Ao que parece, o cônsul se convence da importância em centralizar a supervisão e fiscalização das escolas italianas no estado de São Paulo em nome do conhecimento, amor e respeito à Itália, assim no mesmo dia 1 de março de 1904 escreve para o Ministro das Relações Externas expondo a situação das escolas:

Embora as escolas italianas em São Paulo deixem muito, mas muito a desejar, embora de fato, consideradas nelas mesmas, uma a uma, se encontram no mesmo ponto de antes ( e como se faz a mudar professores, a melhorar os locais escolares, a fornecer às escolas os mobiliários necessários a impedir que de um lugar passem a outro, de acordo com a conveniência do professor [...], como pastores nômades, sem gastar um centavo?), embora somente uma metade dessas se possa chamar com o nome de escola, todos percebem que qualquer coisa foi feita, que tudo o que foi feito, ainda que pouco, foi o que se podia fazer. (DISPACCIO, 1904, p. 2-3) ${ }^{19}$

\section{O cônsul segue afirmando ser necessária a realização de um estudo} acerca das condições econômicas, morais e intelectuais dos professores, para em

\footnotetext{
18 "...ho statuto vigente non fu disculto ma imposto dalla passata Deputazione Scolastica del 1902, e da suo Presidente, R. Console Generale Cav. Attilio Monaco”.

${ }^{19}$ Sebbene le scuole italiane in San Paolo lasciano molto, ma molto a desiderare, sebbene anzi, considerate in se stesse, una ad una, si trovino su per qui nello stesso punto di prima (e come si fa a cambiare maestri, a migliorari i locali scolastici, a fornire le scuole degli arredi necessari a impedire che da un luogo passino in un altro, secondo la convenienza del maestro [...], come pastori nomadi, senza spendere un quattrino?), sebbene soltanto una metà di esse si possa chiamare col nome di scuole, tutti si accorgono che qualche cosa si è fatto, che tutti anzi quel poco che si poteva fare è stato fatto" ( $p .2-3)$
} 
seguida "disciplinar, no limite do possível" (p.5) o corpo docente composto por pessoas de diversos estratos, tais como "professores formados e por indivíduos que nunca estiveram na escola, nem como professores nem como escolares; de pessoas honestas e de vigaristas socialistas, anarquistas e até ladrões e assassinos."(p.5). ${ }^{20}$ Informa que no ano de 1904 duas medidas importantes foram tomadas, a primeira a da supressão do Estatuto da Associação dos professores italianos de São Paulo, e a segunda a publicação de normas para as escolas italianas que aceitem a vigilância do Consulado.

Sobre a criação e a dissolução da Associação é preciso se deter e buscar ao menos algumas hipóteses para compreender o ocorrido. Em 1901 existiam 25 escolas italianas em funcionamento na cidade de São Paulo (ver tabela 1), se comparamos com a tabela 2, identificamos que destas, 14 escolas ${ }^{21}$ não se associaram, ou seja $56 \%$ o que é bastante expressivo, ainda mais se considerar que alguns destes professores proprietários já gozavam de certa projeção entre a comunidade italiana, como por exemplo Francesco Pedatella, da escola Sempre Avanti, Savoia! e Secondo Cazzuola, da escola Elena Cairoli.

Não foram localizadas fontes que permitam compreender os motivos da não adesão, que podem ser relacionados desde à inexistência de um convite, à discordância dos termos do Estatuto, às disputas quanto a definição de papéis a ocupar na Deputazione Scolastica, à divisão de subsídios, dentre outros. O que se pode hipotetizar é que este grupo que ficou fora da Associação exerceu contundente pressão por meio do Consulado, o que resultou na intervenção e dissolução por parte desse. A disputa entre os professores resulta assim, no fim da iniciativa do que representava um maior poder decisório quanto às práticas realizadas no interior das escolas, quanto à distribuição dos recursos sob a

20 "a disciplinare, nel limite del possibile, un corpo d'insegnanti composto di gente di ogni uscita, di maestri patentati e d' individui che non sono mai stati alla scuola, né come maestri né come scolari; di persone oneste e di guasta mestieri socialisti, anarchici e persino ladri e assassini. "(p.5)

${ }^{21}$ As escolas que não se associaram são: Sempre Avanti, Savoia; Luigi Settembrini; Cornelia Gracco; Elena Cairoli; Italia; Unione Italia; Giuseppe Gallian; Principe di Piemonte; Vittoria Colonna; Principe di Piemonte; Alessandro Manzoni; Elena di Montenegro; Francesco Fiorentino; Vittorino da Feltre. 
forma de livros ${ }^{22}$, materiais e dinheiro e por fim, no estímulo a que o Consulado exercesse função centralizadora quanto às definições políticas, pedagógicas e financeiras das escolas italianas em São Paulo.

Cabe também uma ponderação acerca da descrição feita pelo cônsul ao corpo docente. Ao que parece o fim da Associação carrega fortes elementos políticos, ou de perseguição política, a considerar a avaliação feita de que socialistas e anarquistas seriam vigaristas e são apresentados em similitude aos ladrões e assassinos. Haveria dentre os associados socialistas e anarquistas? Este teria sido um dos motivos que corroboraram para a sua extinção? Questões ainda a ser melhor exploradas.

Assim, em 1904 é publicado o documento Normas para o funcionamento das escolas italianas no estado de São Paulo ${ }^{23}$, assinado pelo Cônsul Geral Gherardo Pio di Savoia que inicia reiterando a dissolução da Associação dos professores italianos em São Paulo, ao mesmo tempo em que apresenta a centralidade do Consulado ou de instância a ele relacionado para as definições da vida escolar, tais como a determinação de programa a ser seguido, a distribuição de materiais e subsídios e a inspeção e fiscalização das escolas. Neste documento são estabelecidas as competências de fiscalização das escolas italianas no estado, sendo o vice-cônsul responsável pelas escolas situadas em Santos, Campinas, Ribeirão Preto e São Carlos do Pinhal e cidades de entorno. Para as escolas da capital e seu entorno permanece a Deputazione Scolastica, no entanto, reconfigurada, passando a ser composta por 10 membros italianos residentes em São Paulo nomeados pelo cônsul. O artigo VIII define suas competências:

a) Dar parecer sobre tudo quanto for solicitado pelo Cônsul Geral e que interesse à instrução e às escolas;

b) Compilar e modificar, quando for necessário, o programa de ensino;

${ }^{22}$ Panizzolo (2018a, 2018b) e Barausse (2016) realizaram estudos sobre o envio de livros de leitura às escolas paulistas, sob a forma de subsídio. O estudo dos livros de leitura permite investigar os valores veiculados e prescritos para o fomento da italianidade e dos laços com a pátria-mãe nos estudantes, crianças italianas e filhas de italianos.

${ }^{23}$ No original Norme pel funzionamento delle scuole italiane nello Stato di S.Paolo. 
c) Estabelecer as normas às quais devem ser sujeitas as escolas que desejarem ser reconhecidas pelo Consulado Geral para poder usufruir de sua assistência e proteção;

d) Visitar e inspecionar, por meio de um ou mais de seus membros, durante o ano escolar, as escolas e apresentar a relação das visitas e das inspeções ao Cônsul Geral;

e) Presidir os exames, nas formas e datas preestabelecidas e deliberar a respeito dos prêmios, sua atribuição e distribuição;

f) Levar em consideração as perguntas e as reclamações dos professores e emitir o seu parecer;

g) Distribuir aos mestres, de modo justo e regular o material escolar que o Cônsul autorizar e fornecer às escolas, e os subsídios de qualquer natureza que venham atribuir do Pátrio Governo, da sociedade e de privados em favor da instrução;

h) Examinar as solicitações de subsídios apresentadas pelos professores e oferecer um parecer a este respeito ao Cônsul;

i) Propor, baseado em relatórios, especiais distinções de louvor, de prêmios e de subsídios aos professores mais aplicados e merecedores e quando necessário, procedimentos disciplinares;

j) Propor e fazer o necessário para o incremento da instrução, das escolas e para o melhoramento dos professores. ${ }^{24}$ ( NORMAS, 1904, p. 4-5)

A partir da publicação das Normas para o funcionamento das escolas italianas no estado de São Paulo, uma nova Deputazione Scolastica foi criada e uma subcomissão por ela foi indicada para compilar e modificar os Programas adotados na Península às escolas em São Paulo, o resultado será apresentado a seguir.

24 a) Dar parere su tutto quanto le sará sottoposto dal R. Console Generale che interesse l'istruzione e le scuole; b) Compilare e modificare, quando sia necessario, il programma di insegnamento; c) Stabilire le norme alle quali dovrano essere soggette le scuole che desiderano di venire riconosciute dal R. Consolato Generale per potere fruire della sua assistenza e protezione;d) visitare e ispezionare, a mezzo di uno o più dei suoi membri, durante l'anno scolastico, le scuole e presentare rapporto delle visite e delle rapporto al $\mathrm{R}$. Console Generale; e) presiedere agli esami, nelle forme ed epoche prestabilite,e deliberare rispetto ai premi, alla loro assegnazione e distribuzione; f) prendere in esame le domande ed i reclami dei maestri e dare il suo parere per l'accettazione o meno dal parte del R. Console Generale; g) Distribuire ai maestri, in modo equo e regolare, il materiale scolastico che il R. Console sarà autorizzato a fornire alle scuole, e cosi i sussidi di qualsiasi natura che venissero assegnati dal Patrio Governo, da società e da privati a favore dell'istruzione; $h$ ) esaminare le domande di sussidi presentate dai maestri e darne parere al R. Console Generale; i) Proporre, in base alle relazioni, delle singoli commissioni, speciali distinzioni di lode, di premio e di sussidi agli insegnanti più diligenti e meritevoli e, quando sia necessario, voti di biasimo e provvedimento disciplinari; $\mathrm{j}$ ) Proporre e fare tutto quanto stimerà utile per l'incremento dell'istruzione, delle scuole e per il miglioramento degli insegnanti.( NORME, 1904, p. 4-5) 


\section{A CONSTRUÇÃO DA IDENTIDADE NACIONAL ITALIANA NO CARÁTER DAS CRIANÇAS E ADOLESCENTES}

Conforme já mencionado, o ensino oferecido nas escolas italianas em São Paulo era denominado de curso elementar dividido em inferior composto pela $1^{\mathrm{a}}, 2^{\mathrm{a}}$ e $3^{\mathrm{a}}$ classes, e superior, pela $4^{\mathrm{a}}$ e $5^{\mathrm{a}}$ classes. De acordo com os dados colhidos no documento "Elenco das escolas italianas do estado de São Paulo em 1905 " 25 e aqui apresentados na tabela 3, a maioria das escolas oferecia o curso elementar inferior até a terceira classe, um outro tanto de escolas oferecia o elementar completo, ou seja, da primeira até a quinta série, e algumas poucas criaram um tipo híbrido composto pelo elementar inferior acrescido da quarta série.

Tabela 3- Os cursos oferecidos nas escolas italianas em São Paulo

\begin{tabular}{|c|c|c|}
\hline $\begin{array}{l}\text { ESCOLAS COM CURSO } \\
\text { ELEMENTAR INFERIOR } \\
\left(1^{\mathbf{a}}, \mathbf{2}^{\mathbf{a}}, \mathbf{3}^{\mathrm{a}} \text { SÉRIES) }\right.\end{array}$ & $\begin{array}{l}\text { ESCOLAS COM CURSO } \\
\text { ELEMENTAR INFERIOR } \\
\left(1^{a}, 2^{a}, 3^{a} \text { SÉRIES) E } 4^{a}\right. \\
\text { SÉRIE }\end{array}$ & $\begin{array}{l}\text { ESCOLAS COM CURSO } \\
\text { ELEMENTAR INFERIOR (1 } \\
\left.2^{\mathrm{a}}, 3^{\mathrm{a}}\right) \text { E SUPERIOR }\left(4^{\mathrm{a}} \text { E } 5^{\mathrm{a}}\right. \\
\text { SÉRIES) }\end{array}$ \\
\hline $\begin{array}{l}\text { Cornelia Gracco; } \\
\text { Duca degli Abruzzi; } \\
\text { Elena di Montenegro; } \\
\text { Ferrante Aporti; } \\
\text { Giuseppe Galliano; } \\
\text { Lud. Ant. Muratore; } \\
\text { Luigi Settembrini*; } \\
\text { Orazio Coclite; } \\
\text { Principessa Mafalda; } \\
\text { Progresso; } \\
\text { Regina Elena; } \\
\text { Regina Marguerita*; } \\
\text { Regina Marguerita; } \\
\text { Regina Marguerita; } \\
\text { Roma Intangibile*; } \\
\text { Santa Lucia; } \\
\text { Scuola Italiana; } \\
\text { Scuola Italiana; } \\
\text { Stella d'Italia; }\end{array}$ & $\begin{array}{l}\text { Dio e Popolo*; } \\
\text { Giosue Carducci* } \\
\text { Immacolata; } \\
\text { Italia; } \\
\text { Vit. Emanuele III; }\end{array}$ & $\begin{array}{l}\text { Dio e Patria; } \\
\text { Alessandro Manzoni*; } \\
\text { Dante Alighieri*; } \\
\text { Elena Cairoli*; } \\
\text { Francesco Fiorentino; } \\
\text { Giovanni Bovio*; } \\
\text { Indipendenza* } \\
\text { Principe di Piemonte *; } \\
\text { Principe di Piemonte; } \\
\text { Scuola Italo Francese*; } \\
\text { Sempre Avanti Savoia *; }\end{array}$ \\
\hline
\end{tabular}

${ }^{25}$ No original Elenco delle scuole italiane nello stato di San Paolo nel 1905. 
Studio e Lavoro*;

Umberto I;

Unione Italiana;

Vit. Emanuele II*;

Vit. Emanuele III;

Vittoria Colonna;

Vittorino da Feltre*;

Vittorio Alfieri.

\begin{tabular}{c|c|c}
\hline Total & Total & Total \\
\hline 27 & 5 & 11
\end{tabular}

${ }^{*}$ Curso noturno.

Fonte: Tabela elaborada pela autora com base nos dados reportados em Elenco delle scuole italiane nello stato di S. Paolo,1905.

Merece destaque, conforme indicado na tabela 3, por meio de um asterisco, a oferta de aulas noturnas em funcionamento nas escolas italianas, o que indica a existência de um grande contingente de italianos adultos que para cá vieram sem o domínio do ler e do escrever, mas também a provável frequência de crianças e adolescentes nos cursos noturnos, após uma longa jornada dedicada ao trabalho.

Muito provavelmente a maioria das escolas oferecia somente o curso elementar inferior porque grande parte das crianças estudava até a terceira série e depois ingressava no mundo dos adultos, ou melhor, no mundo do trabalho. Esta hipótese encontra sustentação na descrição feita pelos três professores indicados para compor a Comissão responsável pela redação dos Programas para as escolas elementares italianas do estado de São Paulo², de 1904, Luigi Lievore, proprietário da escola Principe di Piemonte; Cipriano Dell'Acqua, proprietário da escola Dio e Patria; e Alessandro Allegretti (ainda não foram encontradas referências). Segundo eles: "as famílias de modo geral mandam seus filhos à escola até a terceira série e que, portanto, é um fim em si mesma. Quando o jovem sai desta série, deve estar, tanto quanto é possível, preparado a continuar por si mesmo a própria educação" 27 (p. 2).

\footnotetext{
${ }^{26}$ No original Programmi per le scuole elementari italiane dello stato di S.Paulo (Brasile).

${ }_{27}$ No original: "le famiglie in generale mandano i loro figli alla scuola fino al comprimento della terza classe e che perció questa é fine a se stessa. Per cui il giovanetto, uscendo da questa
} 
A Comissão explica ainda ter realizado uma modificação nos Programas adotados na Itália, no sentido de incluir para as escolas italianas do estado de São Paulo um limitado programa local, e como justificativa argumenta que " muitos dos nossos filhos nasceram aqui, muitos passarão a maior parte de sua vida e muitos aqui terminarão sem ter conhecido sua verdadeira pátria, senão aquilo que eles ouviram dizer"28 (p. 2). Desta forma, segundo os membros da Comissão, esta medida de forma alguma é uma conduta antinacional, apenas busca dar condições aos italianos de compreender melhor as relações, pode-se dizer, comerciais do país, como “... cuidar bem de seus interesses, como trabalhar na indústria, em um ofício, sem o conhecimento da língua e as principais medidas do país?"29 (p. 2).

O Programa é proposto para cinco classes e apresenta a Língua Italiana $\left(1^{\mathrm{a}}, 2^{\mathrm{a}}, 3^{\mathrm{a}}, 4^{\mathrm{a}}, 5^{\mathrm{a}}\right.$ classes); Língua Portuguesa $\left(3^{\mathrm{a}}, 4^{\mathrm{a}}, 5^{\mathrm{a}}\right.$ classes); Aritmética Prática (1 $1^{\mathrm{a}}, 2^{\mathrm{a}}, 3^{\mathrm{a}}, 4^{\mathrm{a}}, 5^{\mathrm{a}}$ classes); História, Geografia, Direitos e Deveres-Brasil e Itália ( $2^{\mathrm{a}}, 3^{\mathrm{a}}, 4^{\mathrm{a}}, 5^{\mathrm{a}}$ classes); Caligrafia $\left(1^{\mathrm{a}}, 2^{\mathrm{a}}, 3^{\mathrm{a}}, 4^{\mathrm{a}}, 5^{\mathrm{a}}\right.$ classes); Noções variadas (foco no Brasil); Desenho; Canto, Ginástica, Trabalho Manual, sendo estas cinco últimas sem indicação da série.

Para formar a alma e o caráter das crianças e adolescentes, a escola deveria manter e aprimorar as características étnicas italianas, conservando estreitos os laços com a mãe-pátria, e nas palavras da Comissão, a "verdadeira pátria” por meio do ensino da Língua Italiana e do estudo da História, da Geografia da Itália e de seus grandes vultos e feitos. Assim, o Programa prevê por exemplo, para a $2^{\mathrm{a}}$ série o estudo dos principais fatos históricos da Itália; para a $3^{\mathrm{a}}$ série, o estudo do Risorgimento italiano entre 1848 e 1870 ; para a $4^{\mathrm{a}}$ série fatos e homens notáveis da história romana e da história medieval; para a $5^{\mathrm{a}}$ série cenas sobre o ordenamento político e administrativo do Reino.

classe, deve essere, per quanto è possibile, preparatto a continuare da si la propria educazione" (p. 2)

${ }_{28}^{2}$ No original: "molti dei nostri figli hanno avuto qui i loro natali, molti qui passeranno la maggior parte della loro vita e molti qui la finiranno senza aver conosciuto della loro vera patria se non quel tanto che ne hanno sentito dire" (p. 2)

29 No original: “...tratar bene i loro interessi, come applicarsi ad un'industria, ad un mestiere, senza la conoscenza della língua e delle misure principal del paese?” (p. 2) 
Se comparados os dois Programas, ou seja, o da Associação dos professores italianos em São Paulo, de 1901 e o da Comissão de 1904 os conteúdos daquele primeiro incidiam em um maior número de temáticas relacionadas à Itália e seus grandes nomes, datas festivas, heróis nacionais, paisagens e monumentos. Ao que parece, ao menos no primeiro momento de uma maior centralidade no Consulado, quanto à organização e funcionamento das escolas italianas, não foi diagnosticado como necessária uma ênfase mais expressiva nas temáticas relacionadas, ao que poderia ser denominado de culto à pátria.

Em 1912 foi publicado o documento Regulamento para as escolas italianas no exterior ${ }^{30}$, sob a chancela do Ministro das Relações Externas, Di San Giuliano, do Ministro da Instrução Pública, Credaro e do Ministro do Tesouro, Tedesco. O Regulamento de 43 páginas está organizado em cinco títulos, a saber: dos institutos escolares, disposições gerais; das escolas médias e governativas; das escolas elementares governativas; das escolas subsidiadas; administração e vigilância das escolas no exterior.

Bastante minudente, o Regulamento prevê calendário, período de inscrições e exames, número de alunos por sala, contribuições a serem pagas pelos colonos, funcionamento da biblioteca, programa escolar, conduta de professores, medidas disciplinares para os alunos e para os professores, subsídio entre outros. Um exemplo bastante profícuo é o artigo 13 acerca das festas escolares:

Art. 13 - Em todas as escolas são celebradas as seguintes festas civis : $\mathrm{O}$ feriado nacional do Estado (primeiro domingo de junho) e, onde as escolas estão abertas, a libertação de Roma (20 de setembro);

O aniversário de sua majestade o rei;

O aniversário de sua majestade a rainha;

O aniversário ou o nome do dia (dependendo do uso local) do chefe do estado onde a escola está localizada;

${ }^{30}$ No original Regolamento per le scuole italiane all'estero. 
Passados alguns anos entre a dissolução da Associação dos professores italianos em São Paulo (1901) e o Regulamento para as escolas italianas no exterior (1912) o Consulado se constituiu efetivamente em instância norteadora e reguladora das escolas italianas no exterior. Com o passar do tempo, o amor à pátria foi se constituindo em temática de grande relevância a ser ensinada nas escolas. Dessa forma aos alunos e professores passou-se a exigir, mais do que ler sobre o respeito e devoção à pátria, torna-se crucial manifestá-lo nas mais diversas situações, dentre elas, nas festas cívicas.

\section{CONSIDERAÇÕES FINAIS}

No livro Mitos, emblemas e sinais Ginzburg (1989, p. 52) descreve que por milênios o homem tem sido um caçador, e por isto, aprendeu a "reconstruir as formas e movimentos das presas invisíveis pelas pegadas na lama, ramos quebrados, bolotas de esterco, tufos de pelos, plumas emaranhadas, odores estagnados". Aprendeu ainda a "farejar, registrar, interpretar e classificar pistas infinitesimais como fios de barbas", além de realizar "operações com rapidez fulminante, no interior de um denso bosque ou numa clareira cheia de ciladas". A descrição nos remete ao papel fundamental das fontes para o que o autor denominou de método indiciário, que permite ao historiador, conhecer por meio de rastros, vestígios, sintomas e indícios tempos de outrora.

Ginzburg (2002, p. 43) nos alerta, no entanto, que não basta reproduzir

\footnotetext{
${ }^{31}$ Art. 13- In tutte le scuole sono celebra ele seguenti feste civili:

La festa nazionale dello Stato (prima domenica di giugno) e, dove le scuole sieno aperte, la liberazione di Roma (20 settembre);

Il genetliaco di sua Maestà il Re;

Il genetliaco di sua Maestà la Regina;

Il compleanno o l'onomastico (a seconda degli usi locali) del capo dello Stato ove ha sede la scuola;

La festa nazionale dello Stato medesimo
} 
as fontes, é necessário interrogá-las, ou seja, compreender as condições de aparecimento, os critérios de veracidade e sua intencionalidade:

(...) ao avaliar as provas, os historiadores deveriam recordar que todo ponto de vista sobre a realidade, além de ser intrinsecamente seletivo e parcial, depende das relações de força que condicionam, por meio da possibilidade de acesso à documentação, a imagem total que uma sociedade deixa de si. Para 'escovar a história ao contrário', como Walter Benjamim exortava a fazer, é preciso aprender a ler os testemunhos às avessas, contra as intenções de quem os produziu. Só dessa maneira será possível levar em conta tanto as relações de força quanto aquilo que é irredutível a elas.

Ao buscar as fontes para o estudo das escolas italianas em São Paulo procurei em meio aos vestígios e rastros, elementos que revelassem o que se quer conhecer e, que se encontram ocultos. As fontes localizadas permitem conhecer um pouco da história cotidiana das instituições escolares italianas em terras brasileiras, a criação das escolas, a fundação de uma Associação dos professores italianos em São Paulo com expressiva adesão de professores da cidade de São Paulo e também de outras cidades do estado, a sistematização de seu funcionamento expresso na publicação do Estatuto da Associação dos professores italianos de São Paulo e dos Programas das escolas da Associação dos professores italianos de São Paulo. Mas como alerta mais uma vez Ginzburg é preciso decifrar quais os interesses em jogo, quais "relações de força" estavam presentes?

A pesquisa permite afirmar que as relações entre os vários protagonistas das escolas italianas em São Paulo eram bastante assimétricas. De um lado, os proprietários e professores das escolas italianas que buscavam, por meio de uma quase autogestão, criar mecanismos de proteção e apoio mútuo pela criação de uma Associação composta pelos próprios professores, para assim definir programas, o funcionamento das escolas, e o uso dos recursos financeiros recebidos sob a forma de doações, materiais escolares e subsídios monetários. De outro lado, alguns outros professores que por motivos ainda não conhecidos 
não participaram da Associação, mais do que isto, a ela se opuseram, combatendo-a ferozmente junto aos representantes do Ministério. E ainda, o Consulado que amparado pela legitimidade institucional frente ao Governo Italiano demonstrou na relação de força, supremacia em relação aos outros sujeitos.

Encampando os reclamos dos professores que se negaram a participar da Associação ou que dela tenham sido excluídos, o Consolado a dissolveu eliminado assim, a possibilidade de uma maior autonomia, fosse na realização dos programas, fosse, sobretudo no uso e distribuição de recursos materiais e financeiros, centralizando todas as decisões pedagógicas, financeiras e políticas, quanto à definição dos membros da Deputazione Scolastica.

A partir das fontes encontradas buscou-se compreender como as escolas contribuíram para a constituição de uma identidade étnica italiana. A italianidade, expressa pelo amor à pátria, se fez presente nos programas propostos tanto pela Associação dos professores italianos em São Paulo, quanto pelo Consulado. No Programa da Associação em comparação ao Programa proposto pelo Consulado havia uma maior incidência de temáticas que favoreciam o desenvolvimento dos vínculos com a Itália. No entanto, poucos anos depois, com a publicação do Regulamento para as escolas italianas no exterior (1912) a preocupação com a italianidade ganha muito mais ênfase, requerendo-se por parte de professores e alunos, além do estudo de vultos, datas e fatos, a manifestação expressa do respeito e amor à pátria.

As escolas italianas da cidade de São Paulo podem ser pensadas, de acordo com Panizzolo (2018a, 2018b) como espaços de aprendizagem dos saberes elementares do ler, escrever, calcular, História e Geografia, mas principalmente, como constituidoras de patriotismo, e para isto, delas foi exigido a responsabilidade em "italianizar” os que para cá vieram de uma Itália recém unificada, e os aqui nascidos, que pelo princípio jus sanguinis tinham, segundo o governo italiano, a transmissão da nacionalidade assegurada pela descendência. 


\section{FONTES:}

ALMANACO DEL FANFULLA. Le scuole italiane di S. Paolo.1898. p.397-8. In: Archivio Storico Diplomatico del Ministero degli Affari Esteri, Archivio Scuole, 1889-1910, b.341.

BOLLETINO DEL MINISTERO DEGLI AFFARI ESTERI, 14 AGOSTO 1901, FASCICOLO 204.

BOLLETINO DELLA EMIGRAZIONE, 1902, ANNO 1.

DISPACCIO DEL REGIO CONSOLE GHERARDO PIO DI SAVOIA DEL 1MARZO 1904. In: Archivio Storico Diplomatico del Ministero degli Affari Esteri, Archivio Scuole, 1889-1910, b.341.

DISPACCIO DEL SEGRETARIO SEBASTANO NAVASQUES DEL 1 MARZO 1904. In: Archivio Storico Diplomatico del Ministero degli Affari Esteri, Archivio Scuole, 1889-1910, b.341.

ELENCO DELLE SCUOLE ITALIANE APPARTENIENTI ALLA ASSOCIAZIONE FRA GL'INSEGNANTI ITALIANI IN S. PAOLO DIVISE PER DISTRETTI CONSOLARI.1903. In: Archivio Storico Diplomatico del Ministero degli Affari Esteri, Archivio Scuole, 1889-1910, b.341.

FANFULLA. Il Brasile e gli Italiani. FIRENZE: R. BEMPORAD \&FIGLIO, 1906.

MINISTERO DEGLI AFFARI ESTERI. Annuario delle scuole colonial per I'anno finanziario e scolastico 1888-89. Roma: Tipografia di Gabinetto del Ministero degli affari esteri, 1889.

MINISTERO DEGLI AFFARI ESTERI. Elenco delle scuole italiane nello stato di S. Paolo,1905. In: Archivio Storico Diplomatico del Ministero degli Affari Esteri, Archivio Scuole, 1889-1910, b.314.

PROGRAMMI DELLE SCUOLE DELL' ASSOCIAZIONE FRA GL'INSEGNANTI ITALIANI DI S. PAOLO. S.Paolo: Stabilimento Tipografico a vapore de La Tribuna Italiana, 1901. In: Archivio Storico Diplomatico del Ministero degli Affari Esteri, Archivio Scuole, 1889-1910, b.341.

REGIO CONSOLATO GENERALE D'ITALIA IN SAN PAOLO. Norme pel funzionamento delle scuole italiane nello stato di S. Paolo.1904. In: Archivio Storico Diplomatico del Ministero degli Affari Esteri, Archivio Scuole, 1889-1910, b.341. 


\section{REGIO CONSOLATO GENERALE D'ITALIA IN SAN PAOLO. Programmi} per le scuole elementari italiane dello stato di S.Paulo ( Brasile).1904. In: Archivio Storico Diplomatico del Ministero degli Affari Esteri, Archivio Scuole, 1889-1910, b.341.

REGOLAMENTO PER LE SCUOLE ITALIANE ALL'ESTERO. Milano: Società Editrice Libraria, 1912. (Collezione Legislativa Portafoglio). In: Archivio Storico Diplomatico del Ministero degli Affari Esteri, Archivio Scuole, 1889-1910, b.341.

STATUTO DELLA ASSOCIAZIONE FRA GL'INSEGNANTI ITALIANI DI S. PAOLO. San Paolo: Tipografia Italiana, 1902. In: Archivio Storico Diplomatico del Ministero degli Affari Esteri, Archivio Scuole, 1889-1910, b.339.

\section{REFERÊNCIAS}

ALVIM, Zuleika M. F. Brava gente! Os italianos em São Paulo (1870-1920). São Paulo: Brasiliense; 1986.

BARAUSSE, Alberto. Livros didáticos e "italianidade" nas escolas italianas do Brasil: entre liberalismo e fascismo. In: XI CONGRESSO LUSO-BRASILEIRO DE HISTÓRIA DA EDUCAÇÃO,2016, Porto. Anais...Porto,2016, s/p.

BASSANEZI ET ALII. Atlas da imigração internacional em São Paulo 1850-1950. São Paulo: UNESP, 2008

BIONDI, Luigi. Classe e nação: trabalhadores e socialistas italianos em São Paulo, 1890-1920. Campinas: UNICAMP, 2011.

CENNI, Franco. Italianos no Brasil: "Andiano in Merica”. 3 a ed. São Paulo: EDUSP, 2003.

DE AMICIS, Edmondo. Em alto mar. Tradução de Adriana Marcolini. São Paulo: Nova Alexandria, 2017.

GINZBURG, Carlo. Mitos, emblemas e sinais: morfologia e história. Trad.: Federico Carotti. São Paulo: Companhia das Letras, 1989.

GINZBURG, Carlo. Relações de força: história, retórica e prova. Trad.: Eduardo Brandão. São Paulo: Cia das Letras, 2002.

HALL, Michael. Imigrantes na cidade de São Paulo. In: PORTA, Paula (org). História da cidade de São Paulo: a cidade na primeira metade do século XX. São Paulo: Paz e Terra, v. 3, 2004, p. 121-151. 
KREUTZ, Lucio. Identidade étnica e processo escolar. In: LUCHESE, Terciane Ângela. (org). História da escola dos imigrantes italianos em terras brasileiras. Caxias do Sul: Educs, 2014, p.35-56.

LUCA, Tânia. Regina de. As sociedades de socorros mútuos italianas em São Paulo. In: DE BONI, Luis Alberto. (org). Presença italiana no Brasil. Porto Alegre: Escola Superior de Teologia; Torino: Fondazione Giovanni Agnelli, 1990, p. 383-400.

MALIKOSKI, Adriano; KREUTZ, Lucio. O processo de ensino étnico dos imigrantes poloneses no Rio Grande do Sul (1875-1938). In: SOARES, Eliana Maria do Sacramento; BISOL, Claudia Alquati (orgs). Pesquisa em educação [recurso eletrônico]: olhares históricos e filosóficos, reflexões sobre tecnologias e inclusão. Caxias do Sul: Educs, 2014, p. 71-82. (Coleção educatio; v. 5).

MARCOLINI, Adriana. Introdução. In: DE AMICIS, Edmondo. Em alto mar. Tradução de Adriana Marcolini. São Paulo: Nova Alexandria, 2017, p. 9-16.

MIMESSE, Eliane. O impasse das escolas primárias públicas ao contingente de alunos estrangeiros na cidade de São Paulo no início do século XX. Histórica, São Paulo, ano 8, n. 56, p. 12-19, out. 2012.

PANIZZOLO, Claudia. A escola da Sociedade de Mútuo Socorro Principe di Napoli: o que nos contam os documentos? Raízes, São Caetano do Sul, ano XXIX, n. 56, jan/jun. 2017.

PANIZZOLO, Claudia. Italianizar os brasileirinhos, paulistanizar os italianinhos: um estudo sobre os livros de leitura que circularam nas escolas em São Paulo no início do século XX. In: CASTRO, Cesar Augusto; CASTELLANOS, Samuel Luis Velazquez. História da escola; métodos, disciplinas, currículos e espaços de leitura. Maranhão: EDFUMA, 2018 a, p. 100- 125.

PANIZZOLO, Claudia. Livros de leitura, dizeres e fazeres da escola primária étnica italiana no Brasil entre fins do século XIX e início do século XX: o estudo do livro Piccolo Mondo, letture per le scuole elementari. In: XI CONGRESSO LUSO-BRASILEIRO DE HISTÓRIA DA EDUCAÇÃO, 2016, Porto.

Anais...Porto, 2016 a, s/p.

PANIZZOLO, Claudia. O jornal Fanfulla e a escola étnica italiana em São Paulo: ensinar a ler, escrever, calcular e a ser italiano (1893-1910). In: XIII CONGRESSO IBERO AMERICANO DE HISTORIA DA EDUCAÇÃO, 2018, Montevideu. Anais... Montevideu, 2018b, s/p.

PANIZZOLO, Claudia. Piccolo mondo letture per le scuole elementari: 
mutualismo e educação em uma escola étnica italiana em São Paulo In: MAZZA, Debora.; NORÕES, Katia (org). Educação e migrações internas e internacionais: um diálogo necessário. Jundiai: Paco Editorial, 2016 b, p. 80100.

POMA, Renato. Carta ao leitor. In: DE AMICIS, Edmondo. Em alto mar. Tradução de Adriana Marcolini. São Paulo: Nova Alexandria, 2017, p. 7-8.

POUTIGANT, Philippe; STREIFF-FENART, Jocelyne. Teorias da etnicidade. 2 ed. Trad.: Elcio Fernandes. São Paulo: Fundação Editora da Unesp, 2011.

TRENTO, Angelo. Do outro lado do Atlântico: um século de imigração italiana no Brasil. Trad. Mariarosaria Fabris e Luiz Eduardo de Lima Brandão. São Paulo: Nobel, 1988.

TRENTO, Angelo. Imprensa italiana no Brasil: séculos XIX e XX. São Carlos: Edufscar, 2013.

TRENTO, A. In Brasile. In: BEVILACQUA, Piero; DE CLEMENTI, Andreina.; FRANZINA, Emilio. Storia dell'emigrazione italiana; i arrivi. Roma: Donzelli Editore, 2009, p. 3-23.

TRENTO, Angelo. Os italianos no Brasil. São Paulo: Melhoramentos, 2000. TRENTO, Angelo. Prefácio. In: TRUZZI, Oswaldo. Italianidade no interior paulista; percursos e descaminhos de uma identidade étnica (1880-1950). São Paulo: UNESP, 2016, p. 9-14.

TRUZZI, Oswaldo. Italianidade no interior paulista; percursos e descaminhos de uma identidade étnica (1880- 1950). São Paulo: UNESP, 2016.

CLAUDIA PANIZZOLO Possui graduação em Pedagogia pela Universidade de São Paulo (1991), Especialização em Educação Infantil pela Universidade Metodista de São Paulo (1998), Mestrado em Educação: História, Política, Sociedade pela Pontifícia Universidade Católica de São Paulo (2001) e Doutorado em Educação: História, Política, Sociedade pela Pontifícia Universidade Católica de São Paulo (2006). Realizou estágio pós-doutoral na Universidade de Caxias do Sul-Brasil e na Università degli Studi del MoliseItália (2019). É Professora Associado II da Escola de Filosofia, Letras e Ciências Humanas da Universidade Federal de São Paulo- EFLCH / UNIFESP, atua no Programa de Pós-Graduação em Educação- curso de Mestrado e Doutorado e no curso de Pedagogia, na área de Educação Infantil. Integra a rede transnacional TRANSFOPRESS (França-Brasil). Lidera o Grupo de Estudos 
e Pesquisa Infância, Cultura, História (GEPICH); e participa do Grupo de Estudos e Pesquisa História da Educação, Imigração e Memoria (GRUPHEIM) e do Grupo de Estudos e Pesquisa História da Educação: Intelectuais, Instituições, Impressos. É associada da Sociedade Brasileira de História da Educação (SBHE) e da Associação Nacional de História (ANPUH).

E-mail: claudiapanizzolo@uol.com.br

(D) http://orcid.org/ 0000-0003-3693-0165

Recebido em: 05 de abril de 2019

Aprovado em: 19 de junho de 2019

Revista História da Educação - RHE

Associação Sul-Rio-Grandense de Pesquisadores em História da Educação - Asphe Artigo de acesso aberto distribuído nos termos de licença Creative Commons. 